\title{
Ensino remoto emergencial em matemática e o Milieu didático-virtual: uma reflexão teórico-propositiva em contexto institucional e adverso
}

Emergency remote teaching in mathematics and the didactic-virtual milieu: a theorical-propositive reflection in an institutional and adverse context

Denivaldo Pantoja da Silva ${ }^{1}$

\section{Resumo}

Este trabalho tem como objetivo promover uma reflexão teórico-propositiva sobre Ensino Remoto Emergencial (ERE) considerando alguns aspectos do ensino de Matemática e o ERE como instrumento didático-pedagógico crucial no desenvolvimento de atividades acadêmicas integrado em um sistema de Ensino Remoto Institucional (ERI), entendidos no sentido do Milieu didático proposto pela Teoria das Situações Didáticas (TSD) ressignificado pela Teoria Antropológica do Didático (TAD), no espaço universitário e, ao mesmo tempo, expor de modo propositivo a noção ampliada de Milieu didático-virtual (MD) v ressignificado em contexto adverso de pandemia/pós pandemia da Covid-19. Para isso, recorremos ao estudo bibliográfico-investigativo em documentos específicos, articulados com base na TSD e na TAD. Os resultados do estudo revelam que o modelo de ensino tradicionalmente desenvolvido nas instituições de ensino - básico e superior - se fragilizou diante do estado de pandemia, exigindo mudanças e reconstruções imediatas, entendendo-se que a padronização de métodos de ensino mediados por tecnologias digitais à distância requer estruturação consistente, bem como o modo de entender o ensino de Matemática em milieux remotos que se estabelecem em contexto pandêmico.

Palavras chave: ensino remoto; método de ensino; Milieu; educação superior; reflexão.

\section{Abstract}

This work aims to promote a purposeful reflection theorical-propositive on Emergency Remote Teaching (ERT) considering some aspects of Mathematics teaching and the ERT as a crucial didactic-pedagogical tool in the development of academic activities integrated in an Institutional Remote Teaching (IRT) system, understood in the sense of the didactic milieu proposed by the Theory of Didactic Situations (TDS) resignified by the Anthropological Theory of Didactics (ATD), in the university space and, at the same time, presenting, in a propositional way, the expanded notion of Didactic-Virtual Milieu (DM) $V$ resignified in the adverse pandemic/post-pandemic context of Covid-19. For this, we resorted to the

\footnotetext{
${ }^{1}$ Universidade Federal do Pará | denivaldo@ufpa.br
} 
bibliographic-investigative study in specific documents, articulated based on the TDS and the ATD. The results of the study reveals that the teaching model traditionally developed in educational institutions - basic and higher - has weakened in the face of the pandemic, requiring immediate changes and reconstructions, understanding that the standardization of teaching methods mediated by digital technologies distance requires consistent structuring, as well as the way to understand the teaching of Mathematics in remote milieux that are established in a pandemic context.

Keywords: remote teaching; teaching method; Milieu; higher education; reflection.

\section{Introdução}

O estado de pandemia do novo coronavírus, que acomete a sociedade global, provoca um conjunto de inconvenientes de diferentes ordens, tais como instabilidade, tensões, transformações, isolamento social mudanças na rotina das pessoas em todos os setores da sociedade, obrigando essas pessoas repensarem caminhos diante dos desafios, pensar futuros. No campo educacional, a condicionante pandêmica implica criação de novos cenários de ensino e de aprendizagem em contexto institucional; neste caso, destacamos um problema concreto no ecossistema ${ }^{2}$ universitário, mas que se estende à educação básica: a oferta de atividades acadêmicas, ou seja, de cumprir a tarefa de elaborar um dispositivo didático-pedagógico que atenda plenamente condições de ensino remoto.

Particularmente, se considerarmos, a título de ilustração, um determinado projeto social de ensino já implementado em dada instituição, uma implicação de certa forma imediata recai sobre ele e, que a nosso ver, deve ser apreciado com atenção para ocorrer a (re) organização do contrato estabelecido inicialmente entre as partes da relação didática pelo engendramento de novas cláusulas reguladoras, o que levará, consequentemente, a uma mudança no milieu $^{3}$ didático de interação entre professor, alunos e o saber a ser estudado em razão do contexto de ensino remoto e da rede tecnológica de informação e comunicação digital a serem inseridas nesse processo.

Há diferentes recursos mediados por tecnologias, tais como plataformas digitais, softwares, aplicativos de mensagens instantâneas, dentre outros, formando um aparato tecnológico digital virtual, que definimos como um sistema de informação e comunicação autárquico, o qual disponibiliza ferramentas que facilitam superar dificuldades de interação e comunicação, citando as condições imputadas pela pandemia, que restringem o desenvolvimento de atividades acadêmicas sem presencialidade. É nesse ambiente de interação que se situam diferentes modalidades de ensino à distância (EAD), o ensino híbrido e o Ensino Remoto Emergencial (ERE) (PARÁ, 2020).

É mais ou menos nos meandros desse contexto que pretendemos encaminhar esta reflexão de cunho predominantemente teórico e propositiva, considerando aspectos gerais da ecologia didática dos saberes, pertencente ao escopo da Didática da Matemática que "[...] estuda as atividades didáticas, ou seja, as atividades que têm como objeto o ensino,

\footnotetext{
${ }^{2}$ Neste trabalho esse termo, em sentido amplo, designa um sistema educativo instituído.

${ }^{3}$ Manteremos o termo em francês milieu - plural milieux -, cuja tradução literal para o português brasileiro é meio, não por modismo, mas para manter a amplitude e o sentido que exprime originalmente em estudos de fenômenos didáticos, para além de interpretações de meio ambiente/espaço.
} 
evidentemente naquilo que elas têm de específico para a matemática" (BROUSSEAU, 1986a, p.35), tentando estabelecer possíveis vínculos com o questionamento da real existência do saber, ou inexistência, ou possibilidades de ressurgir na instituição onde se instala ou se instalou (CHEVALLARD, 1991). Tentaremos compreender os questionamentos decorrentes da problemática ecológica posta em relação ao ERE, como ele vive no Ensino Remoto Institucional (ERI), em que sentido surge e como se mantem/manterá "vivo" no contexto adverso e imprevisível de pandemia/pós pandemia, estabelecendo relações com alguns aspectos do ensino da Matemática.

A problemática ecológica, em nosso entendimento, mostra-se pertinente neste contexto reflexivo pois, dentre outros aspectos importantes, está relacionada à ideia de habitat, como o espaço de vida e o ambiente conceitual de um objeto de saber em relação a um ecossistema e também de nicho, lugar funcional ocupado pelo objeto de saber no sistema ou praxeologia dos objetos com os quais interage. De acordo com Chevallard (1994), para os ecologistas o termo habitat de certa forma corresponde ao endereço dos organismos e o nicho às funções que desempenham nesse habitat. Nesse sentido, para ilustrar nossas compreensões vamos considerar a Universidade Federal do Pará (UFPA) com suas unidades (Campi) como habitat situado na Amazônia; as subunidades (Faculdades) e Polos universitários como nichos. Supondo como ecossistema educacional vigente, o habitat corresponde a uma universidade multicampi composta por 12 campi em regiões diversas ${ }^{4} \mathrm{e}$ dezenas de Polos universitários, ${ }^{5}$ distribuídos por mais de 60 municípios paraenses atendendo mais 51 mil alunos, de acordo com a Andifes ${ }^{6}$. Esse conjunto expressivo de pessoas envolvidas acelerou a tomada de decisão institucional pela gestão superior, a contento, em favor da preservação da saúde das mesmas, ao suspender suas atividades presenciais, como medida de biossegurança devido ao avanço da pandemia do novo coronavírus.

É importante destacar o fato inquestionável de que nenhum sistema educativo no mundo foi preparado para enfrentar situações de paralisação inesperada por longo prazo, como este provocado por pandemia. E embora saibamos que exista a possibilidade ínfima de ocorrência, essa demanda exigiria das instituições de ensino a inserção, na formação inicial dos futuros profissionais da educação, capacitações direcionadas em biossegurança que simulassem, por exemplo, milieux hipotéticos como o de pandemia que não admite presencialidade ou aglomeração de pessoas nos espaços físicos.

No entanto, a todo custo precisamos superar, à medida que surgem, as condições restritivas que são impostas à sobrevivência humana. E na educação o desafio parece ser o de buscar novas perspectivas de ensino em contexto geral para promoção das aprendizagens, quer recorrendo ao universo tecnológico virtual, repensando a leitura de mundo, revendo prioridades, replanejando ações didáticas para evitar improvisações e, consequentemente, o surgimentos de efeitos indesejáveis no processo de construção do conhecimento, embora novos projetos educativos sejam sustentados em experiências já

\footnotetext{
${ }^{4}$ Os campi encontram-se nos municípios paraenses de Belém, Ananindeua, Castanhal, Salinópolis, Bragança, Soure, Breves, Altamira, Capanema, Tucuruí, Cametá, Abaetetuba.

${ }^{5}$ O Campus do Tocantins/Cametá - UFPA, por exemplo, possui 04 Polos universitários, presentes nos municípios de Mocajuba, Baião, Oeiras do Pará e Limoeiro do Ajuru, no Estado do Pará.

${ }^{6}$ Associação dos Dirigentes das Instituições Federais de Ensino Superior, responsável pela pesquisa.
} 
vivenciadas no modo presencial, com olhar no presente de ambientes interativos virtuais pouco conhecidos ou até mesmo totalmente desconhecidos do fazer educativo.

Todavia, mesmo com ferramentas digitais adequadas e ultra eficientes ao sistema didático virtual, parece não ser garantia plena de sucesso na aprendizagem matemática, dado o caráter inovador do aparato tecnológico a ser mobilizado de forma urgente nas aulas. Além disso, outras variáveis intra e extra matemáticas atinentes ao milieu do aluno poderão se estabelecer involuntariamente nessa relação, acabando por se integrar como condição restritiva, interferindo diretamente no estudo do objeto matemático. Esses aspectos, necessariamente, já implicam no replanejamento do trabalho docente e no desenvolvimento de novas competências e aquisição de habilidades.

Diante desta urgência imposta pela situação pandêmica e das condições pertinentes ao nosso habitat, consideramos fundamental compreender possíveis relações que podem ser estabelecidas entre o ERE e o milieu, engendrado em contexto de realidade virtual, onde as interações acontecem remotamente por meio de tecnologias digitais. Isto posto, este construto tem como objetivo promover uma reflexão teórico-propositiva sobre Ensino Remoto Emergencial (ERE) considerando alguns aspectos do ensino de Matemática e o ERE como instrumento didático-pedagógico crucial no desenvolvimento de atividades acadêmicas integrado em um sistema de Ensino Remoto Institucional (ERI) - que será discutido adiante - entendidos no sentido do milieu didático proposto pela Teoria das Situações Didáticas (TSD) ressignificado pela Teoria Antropológica do Didático (TAD), no espaço universitário e, ao mesmo tempo, expor de modo propositivo a noção ampliada de Milieu didático-virtual $\left[(\mathrm{MD})_{\mathrm{v}}\right]$ ressignificado em contexto adverso de pandemia/pós pandemia da covid-19. Acreditamos que $(M D)_{V}$ se ajusta à complexidade da realidade social emergente no campo educacional institucional.

Nesse sentido, justificamos e reafirmamos que o desenvolvimento deste trabalho está vinculado ao domínio da Didática da Matemática que "[...] é imenso, e os terrenos dos didatas se encontram virtualmente em todas as partes no espaço social" (CHEVALLARD,1991, p.174, grifo do autor e tradução nossa). Tentaremos oportunizar uma compreensão, mesmo que introdutiva, sobre o caráter científico-formativo da construção de conhecimentos matemáticos em ambientes tecnológicos virtuais desenvolvidos remotamente. Para além dessas expectativas, por vezes panglossianas, novos percursos de enfrentamento às condições desafiadoras configuram instrumentos estratégicos de produção de conhecimento em milieux remotos a serem vivenciados por professores, alunos e demais profissionais da educação.

Portanto, tendo em vista o contexto pandêmico, a realidade digital mediada por inteligência artificial e as condições iniciais apresentadas configuram uma questão que se mostra pertinente compreendermos nesta reflexão: Como se instalou e se mantém o funcionamento das atividades acadêmicas, no contexto de pandemia e pós-pandemia, mediadas por tecnologias digitais via Milieux didático-virtual que se instituem diante do Ensino Remoto Emergencial (ERE) no ERI, de modo a garantir a qualidade do ensino, em particular, de Matemática?

É claro que, do ponto de vista do ensino geral, considerando a amplitude do ERI, partimos da hipótese de que a questão é complexa, cujas respostas possíveis poderão ser construídas e influenciadas pela observância de distintas variáveis didáticas e não didáticas que emergem, no processo, no habitat considerado, em nosso caso, no âmbito da Amazônia brasileira uma região que apresenta dificuldades estruturais e tecnológicas, 
econômica, de mobilidade, saúde e educação. Mais ainda, devemos recorrer às noções da TSD articulada com a TAD e a documentos normativos, potenciais instrumentos de análise de fenômenos educacionais.

Assim, motivado pela intenção de alcançar nosso objetivo, construímos uma estrutura organizada do seguinte modo: na introdução, situamos a problemática em contexto global, evidenciando a inserção do ERI como problemático no ensino geral e no âmbito da Didática da Matemática. Em seguida, compondo a metodologia discutimos a estrutura normativa do ERE na resolução 5294/2020 do CONSEPE/UFPA explicitando procedimentos, medidas, estratégias e possibilidades de ensino contidas na resolução. A Didática da Matemática complementa a discussão metodológica como campo de investigação, destacamos as noções assumidas no marco da Teoria das Situações Didáticas aliadas aos pressupostos da Teoria Antropológica do Didático, a partir do que discutimos a noção de contrato didático e milieu que possibilitou tentar compreender o objeto de reflexão deste trabalho. A discussão específica segue em torno do ERE e a noção ampliada de milieu didático-virtual (MD) como contribuição teórica para o debate em Educação Matemática. Finalizamos destacando os resultados investigativos proporcionados durante seu desenvolvimento.

\section{Metodologia e marco teórico e regimental}

\section{Delineamento generativo do ensino remoto emergencial na resolução $5294 / 2020$}

A gênese do Ensino Remoto Emergencial na UFPA se realizou com a promulgação da resolução número 5294 de 21 de agosto de 2020 pelo Conselho Superior de Ensino, Pesquisa e Extensão (CONSEPE), fundamentada em decisões discutidas nas entidades de oficio inter-relacionadas, respeitando as normativas estabelecidas em escala de níveis de abrangência, indo do local ao global, cumprindo-se a decisão da Câmara de Ensino de Graduação e do CONSEPE e, ainda, considerando os itens seguintes que mostram a amplitude e potencialidade do dispositivo didático-pedagógico:

i) o estado de bem-estar social como direito fundamental do homem assegurado na Constituição da República Federativa do Brasil;

ii) a Declaração da Organização Mundial de Saúde, que decretou situação de pandemia no que se refere à infecção pelo novo Coronavírus;

iii) a Lei No. 13.979/2020, que dispõe sobre as medidas para enfrentamento da emergência em saúde pública de importância internacional representada pela pandemia do novo Coronavirus COVID19;

iv) a decisão do CONSEPE, de 22 de maio de 2020, que referendou a suspensão das atividades acadêmicas e administrativas presenciais na UFPA por tempo indeterminado;

v) a Portaria CAPES No. 55 (29/04/2020); a Portaria MEC No. 544 (16/06/2020) que revogou a Portaria MEC No. 343 (17/03/2020); a Medida 
Provisória No. 934 (01/04/2020); a Portaria MEC No. 617 (03/08/2020); o Parecer CNE/CP N. 05/2020;

vi) as diretrizes elaboradas pela Comissão Acadêmica instituída pelo CONSEPE, em 22 de maio de 2020; e

vii) o que foi deliberado nas $2^{a}, 3^{a}$ e $4^{a}$ Reuniões Extraordinárias do CONSEPE, realizadas em 30 de julho de 2020, em 14 de agosto de 2020 e de 17 a 21 de agosto de 2020 (sessões contínuas) (PARÁ, 2020, p.1).

Como podemos observar nesse extrato, não há dúvidas que os fundamentos que estruturam a regulamentação do documento, materializada nos textos dos artigos, parágrafos e incisos da resolução supracitada, certamente propõem integrar de fato o ERE como alternativa de solução institucional, estabelecido como um instrumento de natureza didático-pedagógica a ser utilizado para efetivação da oferta das atividades acadêmicas no habitat educacional, alinhado com os acontecimentos atuais e assegurado pelas recomendações de órgãos oficiais de saúde pública, provocados pela pandemia no contexto mundial, mostrando que se trata não somente de uma necessidade local, mas sim global que exige cumprir com as condições de segurança sanitária provocada pelo avanço de contaminação pelo novo coronavírus.

Dessa maneira, faz se necessário apresentar os elementos estruturais normativos da resolução integralmente e, eventualmente, fragmentados, que tratam especificamente do ERE, considerando que os mesmos são tomados como base nas discussões e reflexões a respeito dos milieux remotos que o ERE participa nos nichos considerados, buscando estabelecer relações com o ensino de Matemática. Seguimos a abordagem sem preocupações com a ordem em que os artigos, parágrafos e incisos foram expressos no texto original da resolução, pois esta reorganização tem intenção estritamente didática.

Sucintamente, podemos destacar que a resolução 5294/2020 está estruturada em três capítulos e vinte e quatro artigos. O primeiro capítulo trata das disposições preliminares marcado pelo nascimento e instituição do ERE e suas diretrizes. $O$ artigo $1^{\circ}$ desse capítulo refere-se ao caráter excepcional e temporário, definindo-o como uma estratégia de oferta de atividades acadêmicas para os cursos da UFPA no período de emergência sanitária devido à pandemia da Covid-19, garantidas as condições de biossegurança, a inclusão digital de discentes, docentes e técnicos e a qualidade na formação.

Em continuação, o artigo supracitado destaca no inciso primeiro a caracterização do ERE, indicando os objetos de ensino e de aprendizagem que poderão ser mobilizados e recomenda os mecanismos de desenvolvimento metodológico organizados da seguinte maneira:

$\S 1^{\circ}$. Ensino Remoto Emergencial (ERE) compreende um conjunto de estratégias didático-pedagógicas que prescindem do compartilhamento de um mesmo espaço físico entre docentes e discentes e que podem ser efetivadas a partir de:

I. Realização de atividades por meios digitais (salas de webconferência; videoaulas exibidas ao vivo ou gravadas; conteúdos em diferentes linguagens e formatos organizados em ambientes virtuais de ensino e aprendizagem; correio eletrônico; sites de redes sociais; aplicativos de mensagens instantâneas, entre outros); 
II. [...]

III. Organização e apresentação de um conjunto de orientações para realização de atividades pelos(as) discentes (leituras dirigidas; resolução de exercícios; desenvolvimento de projetos e de pesquisas; trabalhos em equipe; produção de conteúdos em diferentes linguagens e formatos; cursos de formaç̧ão e capacitação em diversas temáticas, entre outras) [...]

IV. Estabelecimento, por meios digitais, de canal de contato direto entre estudantes e docentes responsáveis, para organização de atividades de Ensino Remoto Emergencial (ERE), apresentação de cronograma e esclarecimento de dúvidas no decorrer de sua realização (SIGAA; correio eletrônico; ambiente virtual de ensino e aprendizagem; site de rede social; aplicativo de mensagens instantâneas, entre outros), de acordo com as condições estabelecidas entre docentes, discentes e técnicos; [...] (PARÁ, 2020, p.2, grifos nossos).

Entendemos que essa organização aponta categoricamente o caráter virtual imprescindível do ERE a ser estabelecido nas interações virtuais por meio de estratégias didático-pedagógicas caracterizadas pelo não compartilhamento de espaço físico pelas pessoas, garantindo a condição de execução remota provocada pela pandemia; sugere-se o uso de diferentes tecnologias e plataformas digitais disponíveis como ferramentas, espaços de interação e orientação virtuais de trabalho acadêmico, possibilitando até certo ponto o controle do cumprimento de cláusulas contratuais de ensino - que se estabelecem no contrato didático - de forma explícita ou não à distância em milieu didático.

No artigo terceiro, o documento determina a natureza das atividades acadêmicas a serem realizadas no ERE em síncronas e assíncronas; além disso, determina ainda o método de ensino a ser utilizado no período de vigência, compreendido entre setembro de 2020 a fevereiro de 2021, nestes termos denominado Período Letivo Emergencial (PLE) e instituído pelo artigo 4 da resolução. Senão vejamos:

$\S 1^{0}$. Atividades Acadêmicas síncronas são aquelas que possibilitam a interação simultânea entre participantes, que se encontram em espaços físicos diferentes, mas conectados, via internet, a um mesmo ambiente virtual, para o estudo de conteúdos diversos e demais atividades de ensino-aprendizagem.

$\S 2^{\circ}$. As Atividades Acadêmicas síncronas podem ser desenvolvidas por meio de plataformas de webconferência disponíveis na UFPA, tais como Conferência Web RPN (Rede Nacional de Pesquisa), Google Meet e Microsoft Teams, além da possibilidade de utilização de ferramentas síncronas, tais como o Chat (bate-papo) do Sistema Integrado de Gestão de Atividades Acadêmicas (SIGAA) e do Moodle, aplicativos de mensagens instantâneas como WhatsApp e Telegram ou transmissões ao vivo pelo YouTube, entre outros recursos.

$\S 3^{\circ}$. Atividades Acadêmicas assíncronas são aquelas que podem ser realizadas por meio de plataformas, ferramentas digitais e outras estratégias de interação não digital, que possibilitem a comunicação não simultânea entre participantes que se encontram em espaços físicos diferentes, dentro de um prazo pré-estabelecido pelos(as) docentes 
responsáveis pela atividade, pré-estabelecidos e acordados entre docentes e discentes.

$\S 4^{\circ}$. Atividades Acadêmicas assíncronas podem ser desenvolvidas por meio da postagem e organização de materiais e tarefas em Sistemas de Gerenciamento de Aprendizagem (SGA) ou Ambientes Virtuais de Aprendizagem (AVA) disponíveis na UFPA, tais como: SIGAA, Moodle e Google Classroom, além do uso de ferramentas assíncronas, como os fóruns (espaços de discussão) dos AVA, correio eletrônico, questionários, planilhas, agendas, vídeo-aulas, porta-arquivos virtuais (Google Drive, Dropbox, outros) e outros recursos digitais. (PARÁ, 2020, p.3).

Finalizando o primeiro capitulo, deixam-se claras as opções dos métodos de ensino que poderão ser adotados pelo professor no ERE, cabendo-Ihe efetivar a escolha e prever no plano de ensino, a partir do tipo de abordagem que melhor se adequar à atividade ou tarefa planejada: ou atividades síncronas, destinadas às atividades que exigem participação instantânea do aluno com o professor, simulando o ambiente de interação de aulas presenciais onde o professor media as ações didáticas; ou atividades assíncronas, adequadas às atividades que não exigem influência mútua para serem desenvolvidas, permitindo certa autonomia do aluno na execução, diferente das primeiras em que a mediação do processo de ensino e de aprendizagem acontece por meio de ferramentas tecnológicas digitais.

O capítulo segundo aborda as disposições para o estabelecimento do PLE em que foi desenvolvido O ERE, a partir do qual destacamos outros aspectos que consideramos relevantes para esta reflexão que propomos, resumidamente. Nos artigos quinto e sexto, fica contemplada a oferta de componentes curriculares inicialmente previstos ou não para serem ofertados presencialmente no período regular do ano letivo de 2020 nos diferentes níveis de ensino desenvolvidos pela UFPA, priorizando o caráter de flexibilização, tendo em conta as condições de oferta das faculdades em consonância com os professores, "[...] além das características próprias dos componentes curriculares, admitido o uso de atividades síncronas e/ou assíncronas, conforme determina as diretrizes acadêmicas gerais para o Ensino Remoto Emergencial (ERE) [...]" (PARÁ, 2020, p.4).

Os incisos segundo e terceiro do artigo sexto destacam dois aspectos importantes do PLE: um que garante às instâncias colegiadas e suas representações decidirem quais componentes curriculares podem ser adaptados, priorizando atender os alunos concluintes e os ingressantes; já o outro garante que a programação das atividades curriculares podem ser planejadas em ordem diversa daquela prevista no projeto pedagógico de curso, não havendo exigência de pré-requisitos, além das atividades extracurriculares.

Não menos importante, o inciso quarto diz respeito à atividade docente, tratando das alternativas de composição do plano individual de trabalho na impossibilidade da oferta remota de um componente curricular planejado e deliberado pelas instâncias e suas representações, tais como adoecimento do professor, ou o componente não se adaptar ao ensino remoto. Esses aspectos são fundamentais no âmbito específico do desenvolvimento pleno e eficaz do trabalho docente para garantir a entrega de resultado de qualidade social e técnico-científica aos usuários do sistema didático. E ainda:

c) outras justificativas para não adesão à possibilidade de ensino remoto emergencial na vigência de um calendário acadêmico, mesmo nas 
condições atuais, devem ser justificadas e analisadas pela gestão da Unidade.

d) Dada a excepcionalidade, a emergência e as situações previstas nas alíneas anteriores, e persistindo a impossibilidade de o(a) docente participar da oferta de Ensino Remoto Emergencial, o(a) mesmo(a) não terá seu percurso profissional (progressão ou promoção funcional, estágio probatório) prejudicado, considerando a justificativa e o aceite da Unidade. Da mesma forma, o(a) docente não poderá ser prejudicado pelo cancelamento das matrículas dos alunos (PARÁ, 2020, p.5).

Adiante, o artigo $9^{\circ}$ trata da participação do discente nas atividades acadêmicas, apresentando duas opções de curso, o qual pode optar em cursar as disciplinas ofertadas no PLE ou aguardar a oferta no modo presencial de acordo o fluxo normal de oferta das faculdades (nichos) de disciplinas/componentes. Além disso, prevê:

$\S 3^{\circ}$. O(A) discente poderá solicitar à coordenação do curso, a qualquer tempo e sem justificativa, o cancelamento da matrícula em componente curricular ofertado na modalidade de Ensino Remoto Emergencial (ERE), em razão das condições de excepcionalidade que a atual situação de pandemia de COVID-19 impõe.

$\S 4^{\circ}$. O(A) discente que não alcançar aproveitamento no(s) componente(s) curricular(es) ofertado(s) na modalidade de Ensino Remoto Emergencial (ERE) no(s) qual(is) estiver matriculado/a(os/as), conforme os procedimentos avaliativos aprovados pela Unidade/Subunidade, terá sua matrícula automaticamente cancelada, em razão das condições de excepcionalidade que a atual situação de pandemia de COVID-19 impõe (PARÁ, 2020, p.7).

Nesse extrato de texto podemos perceber a preocupação institucional com o nível de aproveitamento/devolução dos discentes nas disciplinas cursadas ao optar pelo ERE; além disso, expõe o caráter excepcional da oferta do PLE em função das condições adversas e imprevisíveis que poderão ocorrer durante o processo de ensino e de aprendizagem na interação com instrumentos digitais à distância, tornando-o extremamente vulnerável a possível fracasso no cumprimento das tarefas de estudo e condicionado às circunstâncias que formam novo milieu didático advindas da pandemia, resguardando o discente de qualquer tipo de prejuízo que poderão surgir durante o processo e que poderá, inclusive, motivar sua desistência ou vir a ter baixo aproveitamento de estudo.

O inciso quinto refere-se ao apoio na dinâmica social de desenvolvimento do ERE quanto à acessibilidade, assistência e acompanhamento estudantil permanente de discentes com deficiência a cargo de setor específico, também responsável pela orientação dos "[...] docentes quanto às especificidades pedagógicas e de acessibilidade comunicacional, de modo a assegurar a inclusão plena desses(as) discentes aos componentes curriculares ofertados de forma remota" (PARÁ, 2020, p.7).

O artigo $11^{\circ}$ e seus incisos, dentre outras questões, tratam da inalterabilidade da carga horária original do componente curricular previsto no projeto pedagógico do curso, do plano de ensino e procedimentos didáticos a serem adotados com a previsão de possíveis 
alterações adaptativas que poderão ocorrer de acordo com as condições específicas de discentes e docentes, considerando a presente situação de excepcionalidade, emergência e qualidade do curso ofertados pela disciplina, podendo variar, com exceção das avaliações, desde totalmente assíncronas até totalmente síncronas, definindo-se ainda a bibliografia a ser utilizada. A partir do artigo 12 ao 15 fica restrito aos procedimentos adotados para efetivação dos trabalhos de conclusão de curso.

Finalmente, no capítulo III das disposições gerais e transitórias, trata-se da oferta pela UFPA (habitat) de atividades de formação para os envolvidos no ERE - alunos, professores e técnicos educacionais -, com intuito de promover a atualização, ampliação e possível implementação de novas técnicas e modalidade de ensino em ambientes digitais remotos; e também para acompanhamento e assessoramento no caso de reprogramação das atividades acadêmicas pelas diretorias das pró-reitorias específicas, bem como auxílio no desenho educacional das atividades de ensino e aprendizagem emergenciais, procedimentos a serem tomados para os componentes que não admitem a realização do ERE, autorizando eventualmente atividades presenciais desde que previamente analisadas quanto à necessidade, acordadas entre discentes, docentes e servidores técnicoadministrativos, autorizadas pelo órgão colegiado da unidade e garantidos a manifestação da representação discente e os protocolos de biossegurança para a sua realização.

Portanto, toda essa estrutura normativa prescrita no texto da resolução no 5294/2020 do ERE certamente possibilitou elementos essenciais que subsidiam a discussão entorno da problemática posta, a inserção do ERE no ERI como elemento primordial do ambiente didático de desenvolvimento engendrado pela situação pandêmica. Desse modo, precisamos abordar as noções de milieu e de contrato didático como ferramentas teóricometodológicas de análise de fenômenos didáticos, para então tentarmos construir uma compreensão/reflexão do ERE admitida neste contexto descrito e, em seguida, propor a noção ampliada de milieu didático-virtual $(M D)_{V}$ contido em conjunto de milieux agregados à distância. É o que faremos a seguir.

\section{Didática da Matemática: as noções de contrato didático e milieu}

As noções que abordamos de contrato didático e milieu decorrem de trabalhos disponíveis de Guy Brousseau, compondo o escopo da TSD eventualmente articuladas com os da TAD e outros autores que tratam do tema em voga. Embora essas noções teóricas sejam de algum modo imbricadas, por motivo didático abordamos separadamente, como uma maneira de garantir a evidência de sua essência particular e, ao mesmo tempo, destacar possíveis interrelações importantes de se estabelecerem, a respeito do desenvolvimento do ERE e os aspectos do ensino de Matemática.

Nossa abordagem tenta preservar a ideia original da noção ao realizar as transcrições dos textos livremente, para entender tais relações estabelecidas no processo de ensino e de aprendizagem matemática na presença do $(M D)_{V}$ onde o ERE participa, sob condições de pandemia e pós-pandemia e, ao mesmo tempo, promover uma reflexão sobre a temática posta no cenário prototípico da Amazônia brasileira em referência ao ERI. 


\section{Sobre o contrato didático}

A noção fundamental de contrato didático proposto pela TSD, tomada como instrumento teórico-metodológico para modelar fenômenos didáticos, constitui-se em documento simbólico formado pelo conjunto das obrigações recíprocas e das "sanções" que cada parceiro na situação didática impõe ou acredita impor, explicita ou implicitamente, aos outros e aquelas que são impostas ou que acredita que são impostas a ele sobre o conhecimento envolvido.

Entendemos que a essência da noção de contrato didático está de fato evidente, quando interpretado, de acordo com Brousseau (1988), como resultado de uma "negociação" frequentemente implícita das modalidades de estabelecimento das relações entre um aluno ou um grupo de alunos, um determinado milieu e um sistema educativo. Pode-se ainda considerar que as obrigações do professor para com a sociedade, que the delega sua legitimidade didática, são também parte determinante do "contrato didático".

No entanto, sobre a natureza abstrata e simbólica dessa noção, Brousseau afirma que o contrato didático não é, de fato, um contrato verdadeiro, porque não é explícito, nem livremente consentido, pois nem as condições de ruptura, nem as sanções podem ser dadas antecipadamente, uma vez que a natureza didática dele, que é a importante, depende de um conhecimento ainda desconhecido dos alunos. Além disso, é frequentemente insustentável.

O contrato didático coloca o professor perante uma verdadeira injunção paradoxal, isso quer dizer o seguinte: tudo o que ele faz para que os alunos produzam o comportamento que espera tende a reduzir a incerteza do aluno, privando-o das condições necessárias para compreender e aprender a noção matemática em questão, de maneira que aquilo que professor diz ou significa o que quer que o aluno faça, só pode obtê-lo como a execução de uma ordem e não através do exercício do seu conhecimento e julgamento (BROUSSEAU, 1988).

Brousseau destaca ainda que o aluno, parceiro indispensável da relação didática, do mesmo modo é também confrontado com uma injunção paradoxal, ou seja, se aceitar que, de acordo com o contrato, o professor the ensina as soluções e as respostas, não as estabelece por si só e, portanto, não se compromete com os conhecimentos necessários e não pode se apropriar deles; querer aprender, implicaria então para ele recusar o contrato didático proposto para se encarregar do problema de forma autónoma. Nesse caso, a aprendizagem será, portanto, baseada não somente no bom funcionamento do contrato, mas sim nas suas rupturas e ajustamentos que ocorrem na vigência do mesmo. Quando há uma ruptura - entendida como uma falha do aluno ou do professor -, os parceiros se comportam como se tivesse havido, de fato, um contrato firmado entre eles.

Em suma, para Brousseau o contrato didático é uma forma de definição de uma situação didática. Conceitualmente, são equivalentes essas noções, mas a situação permite elaborar um inventário de contratos de acordo com a distribuição de responsabilidades entre o professor e o aluno. Em nossa compreensão, tais obrigações previstas são relativas às aprendizagens esperadas que, certamente, resultarão do processo educativo e estão diretamente associadas às condições determinadas por tudo o que se entende por milieu, daí a necessidade de compreendermos essa noção. É o que tentaremos fazer a seguir. 


\title{
Sobre a noção de milieu
}

De acordo com Almouloud (2007), o avanço dos estudos realizados por Brousseau (1986) se tornam um marco para a Didática da Matemática que passou assumir investigações com foco no estudo do objeto matemático a ensinar. Com base no construtivismo de Piaget, Brousseau inaugura uma linha investigativa cujos pilares da aprendizagem são sustentados pelas noções de ação, adaptação e equilibração do sujeito e o milieu. Nessa linha, a atenção deve ser dada à forma de apresentação dos objetos matemáticos ao aluno.

A TSD, enquanto modelo explicativo de fenômenos educativos, de acordo com Almouloud (2007), propõe-se a modelar os processos de ensino e aprendizagem da Matemática pelo estudo das interações efetivas do aluno com o milieu organizado em uma situação a-didática. Nesse sentido, a busca de situações fundamentais e a estruturação do milieu têm por objetivo:

\begin{abstract}
Identificar as condições que devem ser consideradas no desenvolvimento de situações (contrato, milieu, situações-problema) afim de propiciar uma aprendizagem significativa. [...] é preciso organizar e desenvolver situações a-didáticas e estabelecer um contrato didático que promove a devolução destas, oferecendo assim condições ao aluno para participar ativamente no processo de produção de seus próprios conhecimentos (ALMOULOUD, 2007, p.189).
\end{abstract}

Desse modo, o extrato de texto nos apresenta a importância das noções de contrato didático e milieu no processo de estudo de um objeto de ensino, em particular, dos objetos matemáticos. Em contexto geral, contribuem sobremaneira para compreensão do funcionamento de um projeto social educativo idealizado por uma dada instituição onde são construídas relações entre professor, alunos e um saber.

Em termos de conceitualização, um glossário ${ }^{7}$ produzido por Brousseau (1988), com data de publicação em 2010, apresenta a seguinte definição de milieu: um sistema antagonista (antagônico) do actante (atuante). Actante representa "aquilo" que, no modelo, atua sobre o milieu de forma racional e econômica no quadro das regras da situação. Como modelo de um aluno ou, de um modo mais geral, de um sujeito, ele atua em função do seu repertório de conhecimentos. Especificamente, quando observado em uma situação de ação, o "milieu" é tudo aquilo que age ou atua sobre o aluno e/ou sobre o que o aluno age ou atua.

Certamente essa afirmativa traduz de modo preciso o significado do milieu didático do aluno; em nossa compreensão a noção propositiva de Milieu didático-virtual que estamos tratando diante do ERE, concordamos inteiramente com o sentido posto por Brousseau, como parte de um conjunto de milieux que se estabelecem na relação didática - sendo essa "habitualmente descrita como uma relação entre dois parceiros: o ensinante e o aluno, com um saber" (BROUSSEAU, 1988, p. 313, tradução nossa) - necessariamente estabelecida à distância, mediada por instrumentos tecnológicos digitais, sob condições adversas provocadas pela pandemia.

\footnotetext{
${ }^{7}$ Reiteramos que traduzimos, de forma livre, esse e outros documentos consultados para atender nossos propósitos.
} 
Entendemos que essa formulação integra e se coaduna à compreensão sistêmica proposta Almouloud (2007) ao afirmar que:

o milieu é o sistema antagônico ao sujeito, sem intenções didáticas, exterior ao sujeito, mas, por suas retroações as ações do sujeito, permite uma reflexão sobre a ação e adaptação. O milieu de uma situação fundamental é um milieu para a aprendizagem do saber em jogo (ALMOULOUD, 2007, p.194).

Ainda assim, temos que considerar que um dos axiomas, de acordo com Brousseau (1988), que sustenta a TSD, garante: para todo conhecimento, é possível construir pelo menos um jogo formal, comunicável, sem utilizar este conhecimento, e para o qual, no entanto, determina a estratégia otimizadora. Desse modo, Brousseau (1988) define que a situação é uma associação descrita por "Interação, Jogo-Jogador, Conhecimento" simbolicamente denotada pela seguinte expressão:

\section{$S\left(I_{t}(X, J), C\right)$}

Nesse modelo simbólico, $S$ representa situação, $I_{t}$ interação realizada no instante $t, X$ jogador e J o jogo. Assim, entende-se que a relação de $X$ com o conhecimento $C$ no instante té, portanto, entendida por intermédio de uma função de $C$ no jogo J.

Brousseau (1988) observa ainda que o sistema antagônico do jogador, em uma situação, é válido, tanto para o jogador quanto para o observador, nesse caso, o milieu é um modelo de parte do universo que refere o conhecimento em jogo e as interações que este determina. Ele desempenha um papel central na aprendizagem como causa de adaptações e no ensino como referência e objeto epistemológico. Portanto, "[...] o milieu é um jogo ou parte de um jogo que se comporta como um sistema não finalizado" (BROUSSEAU, 1988, pp.320-321, tradução nossa).

Para além dessa definição, há que se considerar outro aspecto importante, o caráter relativo do milieu. Brousseau (1988) orienta que, para o professor, uma situação s - não didática, entendida no sentido de que o conhecimento deve ser introduzido pelo próprio aluno - de fato poderá aparecer como um meio (didático) de ensino a ser implementado e, portanto, deve constituir o ambiente no qual irão imergir seus alunos. Esse ambiente constituirá o milieu M com o qual o aluno irá interagir de acordo com as restrições de uma situação didática S (que ele escolheu ou não). Assim, o aluno (colocado) nesta situação S pode ter que interagir com um (outro) sistema que constituirá o milieu m o qual certamente deve compreender e dominar.

Esse é o sentido declarado por Brousseau que tenta demostrar em sua tese e em outros trabalhos publicados que abordam a noção de milieu. Para ele, na relação didática:

[...] é possível mostrar que o milieu é um conceito, não contingente, mas necessário, na teoria das situações, ou seja, que devemos introduzi-lo na teoria não porque descreve um observável conveniente, mas porque é indispensável à especificação da relação didática. (BROUSSEAU, 1988, p.321, tradução nossa).

Quanto à materialidade do milieu de uma noção matemática, reforça ainda mais a ideia fundamental proposta anteriormente do Milieu didático-virtual. Para Brousseau, a estruturação do milieu didático do aluno revela um entrelaçamento de situações correspondentes a projetos distintos onde cada um serve de milieu para o próximo, diante 
do que entendemos que, como processo, o ensino ocorre por meio de um encadeamento de milieux que Ihe dá suporte. Especificamente, o milieu de um conceito matemático é o agregado de milieux de situações em que os conhecimentos relacionados a esse conceito aparecem como um meio de resolução. Assim, por exemplo, a folha de papel, a régua graduada e o compasso engendram o milieu da geometria plana euclidiana (BROUSSEAU, 1988).

A compreensão de Rilhac (2007) amplia e fortalece os recursos teóricos desta reflexão, vai ao encontro de nossa proposição quando afirma: um milieu pode ser definido como um conjunto de objetos de saberes (materiais e simbólicos) geradores de recursos e de restrições. No entanto, existe a recomendação que, no plano teórico, o contrato didático não poderia constituir a totalidade do milieu sob pena de "destruir" a relação didática.

Em relação à abordagem antropológica do milieu elaborada por Chevallard (1988) citado por Brousseau se mostra favorável. Para ele:

[...] a sua abordagem antropológica, tão excitante e promissora, para confrontar com os produtos da abordagem sistêmica que começamos a conhecer. Não me parece que haja contradições importantes entre elas. Pelo contrário, a apresentação do meu tema poderia ganhar em clareza, precisão e eficácia se eu o utilizasse (BROUSSEAU, 1988, p.311).

Para Brousseau, a proposta de Chevallard (1989) representa uma tentativa de precisar o fundamento antropológico da noção de milieu, inserindo-o no âmbito das instituições, como podemos perceber no fragmento seguinte.

Durante a evolução temporal da instituição dos subsistemas do sistema geral de objetos institucionais vão se estabilizar duravelmente, no sentido de que as relações institucionais com esses objetos vão, sobre um período bastante longo, cessar de evoluir, revelar-se "robustos" ... e se naturalizar tornando-se transparentes aos atores da instituição [...] Tais subsistemas de objetos irão assumir, para os atores da instituição, uma função de milieu, parecendo aqui dotado de uma objetividade que escapa ao controle e à intencionalidade da instituição (CHEVALLARD, 1989 apud BROUSSEAU,1988, p.321).

Nesse caso, "poder-se-á então dizer que o milieu é "a-institucional"" (CHEVALLARD,1989, p. 215, apud MARGOLINAS, 1995, p.3). Margolinas chama atenção para uma particularidade observável de funcionalidade, a articulação da concepção de Chevallard sobre a função do milieu com a de Brousseau sistêmica parece possível desde que sejam considerados pontos de vistas distintos: Chevallard no sentido "macro didático" e Brousseau, "micro didático". Assim, em uma dada situação particular, o "milieu" no sentido macro didático é o conjunto de objetos candidatos a fazer parte do "milieu material" da "situação objetiva".

Para concluir esse ponto, destacamos outras ideias complementares propostas por Chevallard (2007) sobre a dialética das mídias e dos milieux, onde estabelece relações importantes para o entendimento da noção de milieu, embora considere a noção semelhante ao milieu a-didático proposto na TSD, isto é, o milieu é todo sistema que possa ser considerado desprovido de intenção na resposta que pode se dar, de maneira explícita ou implícita, a uma certa pergunta. O sistema considerado comporta-se então, a este respeito, como um fragmento da "natureza". Em contraste, as mídias de comunicação social 
são normalmente movidas por certa intenção, por exemplo, a intenção de "informar". Portanto, uma mídia pode, em relação a uma pergunta particular, ser vista como um milieu e também utilizada como tal.

Portanto, essa caracterização que articula as noções de mídias e milieu, uma mídia pode ser entendida como:

[...] palavra que designará qualquer sistema de representação de uma parte do mundo natural ou social endereçado a um determinado público: o "curso" do professor de matemática, um tratado de química, o jornal de um apresentador de TV, um diário regional ou nacional, um site, etc., neste sentido, entram no sistema das mídias (CHEVALLARD,2007, p.1, tradução nossa).

Nesse sentido, podemos entender que a noção de mídias permite também, por extensão, compreendermos o ERE como tal, isto é, parte do milieu do aluno que se constituirá em milieu didático, ou ainda, uma mídia utilizada na interação dos atores da relação didática alunos, professor e o saber, fazendo funcionar a engrenagem do aparato tecnológico disponível para execução das atividades acadêmicas do habitat considerado em nicho determinado. Estas compreensões, portanto, direciona-nos no sentido de discutir o ERE situado.

\section{Aproximações entre ERE, ensino de matemática e a proposição do} Milieu didático-virtual (MD) $)_{v}$ no contexto do ensino remoto institucional (ERI)

Ao refletirmos sobre possíveis relações/aproximações entre ERE e alguns aspectos de ensino de Matemática, vislumbramos expectativas, desafios e, ao mesmo tempo, continuaremos apresentando de forma propositiva a noção de milieu que designamos de Milieu didático-virtual $(\mathrm{MD})_{V}$, pensado com base neste contexto de pandemia prospectando o pós-pandemia, considerando o caráter ternário da construção do conhecimento científico-formativo-analítico. Nesse sentido, ousamos propor nova ferramenta que poderá ser inserida no rol de um sistema de análise e explicativo de fenômenos didáticos, tendo em conta os artefatos tecnológicos tais como plataforma virtuais que se integram ao Milieu didático remoto, não somente os previstos na resolução normativa do ERE do habitat considerado, mas também que possam ser ampliados, alcançando qualquer ecossistema determinado. Para além dessas expectativas, supomos prospectar estratégias eficientes e customizadas de produção de conhecimento em milieux constituídos no contexto do ERI.

Essa ampliação anunciada, conforma o aparato tecnológico que constitui o ERI ao qual - ERE passará a se integrar de modo explícito, não somente para o ensino a distância previsto pela Lei de Diretrizes e Bases da Educação Nacional no 9393 de 20 de dezembro de 1996 no artigo 80 regulamentado pelo decreto nº 9057 de 25 de maio de 2017, na UFPA prevista no Regulamento do Ensino de Graduação aprovado pela resolução no 4399 de 14 de maio de 2013, como a plataforma virtual Moodle que disponibiliza cursos realizados remotamente, mas também para outras finalidades a exemplo do Sistema Integrado de Gestão de Atividades Acadêmicas (SIGAA), o Sagitta - ferramenta tecnológica utilizada para automatizar a realização de chamados para solução dos mais diversos problemas que possam ocorrer com os equipamentos de informática - e o Sistema de Bibliotecas (SIBI/UFPA) composto por 36 bibliotecas universitárias dentre outros. 
É importante notar que essas ferramentas tecnológicas de informação e comunicação apresentadas anteriormente, já existem no habitat institucional anterior à pandemia da covid-19, portanto já eram integrante ao milieu do ERI antes mesmo do ERE se tornar explicito ao ser promulgado como alternativa possível para o desenvolvimento das atividades acadêmicas em situação de pandemia, ou seja, foi uma condição emergencial que possibilitou a implementação por meio da resolução 5294/2020.

$\mathrm{Na}$ realidade, integra-se ao ERI não somente esses sistemas apresentados anteriormente, mas sim todo e qualquer componente pertencente ao habitat UFPA que utilize ferramentas, sistemas, plataformas e interatividade por meio de tecnologias digitais de informação e comunicação. O Centro de capacitação (CAPACIT) promove formação a distância por meio de webinário, o Centro de Tecnologia da Informação e Comunicação (CETIC) responsável pela manutenção das comissões que decidem assuntos relacionados a políticas de tecnologias da informação e comunicação, implantação de sistemas, segurança e serviços de rede. Elabora o plano diretor de tecnologia da informação. E ainda podemos incluir os infocentros e laboratórios de informática disponibilizados nas unidades acadêmicas.

Como posto na resolução 5294/2020, o ERE foi elaborado com papel razoavelmente definido, um dispositivo institucional didático-pedagógico normatizado para viabilizar a oferta e a execução das atividades acadêmicas no âmbito da UFPA de modo excepcional e temporário. Desse modo, podemos dizer então que no sentido do ERI a proposição do ERE se amplia e passa a se integrar ao milieu institucional.

Mesmo com a tendencia de regressão ou de término da pandemia, a UFPA sinaliza a permanência da modalidade remota de ensino ao publicar posteriormente à resolução do ERE, por "necessidade de regulamentar normas e procedimentos para planejamento e execução de medidas de retorno gradual à presencialidade nas atividades de ensino e aprendizagem nos cursos de Graduação e Educação Básica, Técnica e Profissional da UFPA" (PARÁ, 2021, p.1).

Mas, podemos inferir do ERE que, se por um lado o caráter excepcional permite eventuais complementos ou ajustes nas normas previstas sem provocar prejuízos didáticos ou insegurança jurídica, de modo a garantir as especificidades dos cursos ofertados pelos nichos - doravante representadas pelas subunidades acadêmicas ou faculdades - quando prioriza a flexibilização em consonância com as condições de oferta dos mesmos e com os atores da relação didática, por outro, o caráter temporário parece dizer respeito, especificamente, ao período finito de vigência adequado à condição de pandemia implementado pelo período letivo emergencial.

Esses aspectos são importantes e devem ser observados pelos nichos envolvidos, pois possibilitam um delineamento mais preciso do $(M D)_{V}$ e não degeneram sua funcionalidade principal que é a didática, haja vista que parece inerente ao ERE a obediência a um ciclo temporal finito para atender uma emergencialidade de distanciamento social devido à pandemia, mais ou menos no sentido dos "objetos de ensino que sofrem a ação do tempo didático, estão submetidos a uma erosão e a um desgaste "moral" que pressupõe sua renovação no curso de um ciclo de estudo, chamado fenômeno de obsolescência interna ou relativa" (CHEVALLARD, 1991, p.79, tradução nossa). Esse fenômeno difere sobremaneira o ERE da modalidade EAD que perdura por tempo indeterminado; esse talvez seja a trilha a ser seguida pelo ERE a seu modo peculiar. 
Quanto ao fazer matemático, em geral marcado pela recorrência à uma axiomática ${ }^{8}$ para resolução de problemas de situações em contextos, admitamos que um quesito importante nesse processo seja compreender a necessidade de organizar e desenvolver situações a-didáticas que permitam essa recorrência, estabelecer um contrato didático capaz de promover a devolução didática no sentido de Brousseau; a estruturação do milieu didático do aluno ganha importância expressiva por alcançar uma dimensão para além da imbricação direta na relação didática e nos instrumentos e plataformas digitais escolhidos ou não pelo aluno para constituir o $(\mathrm{MD})_{V}$, de certo modo, servirão de parâmetros para mediar a evolução do processo de estudo e à construção do conhecimento matemático em jogo.

Nessa linha, o ERE, enquanto dispositivo didático que normatiza a oferta das atividades acadêmicas reúne um conjunto de estratégias didáticas associado às redes de comunicação e informação virtuais tais como plataformas interativas, ferramentas digitais, sistema de gerenciamento de aprendizagem virtuais e outras interações não digitais, tende a viabilizar sistematicamente o processo de construção do conhecimento, aqui considerado o matemático, transformando $\bigcirc(\mathrm{MD})_{V}$ comparativamente como superestrutura didática (CHEVALLARD, 2009) digital, embora sua efetivação dependa de condições outras que permitam o pleno funcionamento, tais como a conectividade via internet, fato que no contexto da Amazônia se mostra ainda como desafio, equipamentos eletrônicos compatíveis com o estudo do objeto proposto, dentre outras.

Essa caracterização da estrutura digital apresentada que se integra à constituição do $(M D)_{V}$ aponta pelo menos duas dimensões de formação e desenvolvimento que precisam ser avaliadas no contexto do ERE: uma infraestrutural tecnológica virtual e outra de cunho metodológico. A primeira dimensão tem seu fundamento epistemológico na natureza da interação com a atividade proposta ou a ser desenvolvida no estudo do objeto de ensino já definidas, síncrona e assíncrona. A segunda, fundamenta-se no campo das metodologias de ensino aplicadas para desenvolver a atividade planejada de forma a atender a situação factual de forma eficaz para as aprendizagens. A imbricação dessas dimensões, observadas as variáveis intermitentes que poderão surgir, parece ser o desejado, pois viabilizariam satisfatoriamente a construção do conhecimento com a vantagem adicional de prescindirem o compartilhamento de um mesmo espaço físico entre docentes e discentes, condição da realidade atual do ensino ser remoto.

Sobre a infraestrutura digital que se desenha para $O(M D)_{V}$, podemos destacar duas modalidades previstas na resolução normativa para desenvolver as atividades acadêmicas síncronas e as assíncronas. As primeiras integrante do ERI, possibilitam a interação simultânea entre participantes da relação didática, que se encontram em espaços físicos diferentes, mas conectados, via internet, a um mesmo ambiente virtual, para o estudo de conteúdos diversos e demais atividades de ensino e aprendizagem, sendo desenvolvidas em plataformas destinadas a webconferência, com a possibilidade de utilização de ferramentas digitais, tais como chat, aplicativos de mensagens instantâneas ou transmissões ao vivo, aparato que são disponíveis e que podem ser utilizados para fins didáticopedagógicos.

\footnotetext{
8 "A apresentação axiomática é uma apresentação clássica da matemática" (BROUSSEAU, 1986a, p.35).
} 
Já as atividades designadas por assíncronas - realizadas por meio de plataformas, ferramentas digitais e outras estratégias de interação não digital, possibilitando a comunicação não simultânea entre participantes, dentro de um prazo pré-estabelecido pelos(as) docentes responsáveis pela atividade, pré-estabelecidos e acordados entre docentes e discentes -, que compõem $\circ(\mathrm{MD})_{V}$, podem ser desenvolvidas por meio de postagem e organização de materiais e tarefas em sistemas de gerenciamento de aprendizagem (SGA) ou ambientes virtuais de aprendizagem (AVA), além do uso de fóruns, correio eletrônico, questionários, planilhas, agendas, videoaulas, porta-arquivos virtuais e outros recursos digitais que podem ser utilizados com o mesmo fim das primeiras.

É evidente que a escolha do (s) instrumento (s) de interação digital ideal para o ensino da Matemática no mundo diverso de plataformas e softwares digitais possíveis e disponibilizados no (MD) não se constitui tarefa fácil, mas sim complexa; basta considerar a especificidade do processo histórico-epistemológico do objeto matemático, o que não implica a inviabilidade de utilização do aparato digital componente do milieu do ERI necessário para o funcionamento do ERE, posto que em alguns momentos da atividade matemática são fundamentais para compreender o estado de variabilidade do objeto, aplicabilidade ou de estrutura, exigindo, certamente, planejamento do ensino, familiaridade com a ferramenta digital a ser mobilizada na interação, experiências e métodos os quais os docentes não foram preparados na sua formação inicial. Destacamos que todo esse conjunto de recursos proporcionados pelas tecnologias digitais aplicados remotamente não garante o sucesso pleno da aprendizagem em Matemática ao ser comparado com o ensino presencial.

No entanto, neste cenário ousamos postular que a noção de $(M D)_{V}$, como objeto teórico, apresenta-se com característica agregadora; em sua infraestrutura integra entes materiais e imateriais atípicos às práticas educativas ordinárias, sem desprezá-las, dada a modalidade de ação ser remota, embora não controláveis, garantindo o desejado por Brousseau: ir além da conceitualização clássica de milieu didático, assumindo, inclusive, o princípio fundamental de desenvolvimento onde as aprendizagem são sustentadas pelas noções de ação, adaptação e equilibração do sujeito, organizado por uma situação adidática, respeitando a devida atenção dada à forma de apresentação dos objetos matemáticos ao aluno, podendo escolher a estratégia didática conveniente entre síncronas, assíncronas e ainda combinações delas.

Nesse sentido, vimos que a ideia principal que rege o funcionamento efetivo do (MD) $v$ diz respeito ao questionamento de customização e ergonomia do milieu, aspectos que podem garantir o sistema antagônico do sujeito que nele atua em sentido ampliado, ou seja, o atuante ganha no contexto de pandemia e pós pandemia novas possibilidades de interatividade via redes virtuais de aprendizagens nas quais participam da relação didática não somente as ferramentas digitais de inteligência artificial, mas também variáveis emocionais decorrentes da interação virtual e circunstanciais humanas, no sentido em que o "milieu" é tudo aquilo que age ou atua sobre o aluno e/ou sobre o que o aluno age ou atua.

\section{Considerações e resultados}

Como podemos observar, tentamos seguir a direção intencional de discutir as noções teóricas que julgamos pertinentes ao tema proposto sob as condições de contexto 
pandêmico, visto que aflige todos os sistemas sociais. Os resultados apontam que foi nesse ambiente que o ERE se tornou explicito em um sistema de interação digital que integra o ERI. Não foi nosso propósito exaurir todas as possibilidades de discussão que o tema em questão exige, e sim promover uma reflexão de revisão teórica e propositiva, sobre novos mecanismos e dispositivos educacionais que emergem no contexto geral do ensino; neste caso, centramos nossa atenção na modalidade remota e emergencial em tempo de pandemia, o qual revelou um conjunto de dificuldades que exigem replanejamento das práticas docentes rotineiras por conta de novas variáveis que condicionam a vida de todos, em particular, da população que vivem na Amazônia brasileira.

Por outro lado, se observarmos os componentes curriculares específicos, a exemplo da Matemática, não estão livres do enfrentamento de dificuldades engendradas pela pandemia durante o processo de ensino e de aprendizagem, como a instabilidade de conexões com a internet na transmissão de aulas remotas, falta de equipamentos tecnológicos adequados ao aluno e ao professor, estrutura física adequada; além disso, condições de vulnerabilidade social discente, prioridades de visualização dos assuntos disponíveis na rede web, estado emocional desfavorável dentre outras que influenciam diretamente no êxito da construção do conhecimento matemático.

Certamente novos incitamentos por força didática também surgirão no processo educativo remoto, mas que com o passar do tempo devem ser superados. E, à medida do possível, as práticas de ensino devem passar por remodelações para atender às demandas emergentes, segundo as especificidades do saber em jogo, como, neste caso, a Matemática, que exige atenção particular no desenvolvimento de competências e na aquisição de habilidades de forma efetiva, padrão regular de interações simultâneas entre os atores da relação didática: alunos, professor e o objeto matemático.

Estas discussões parecem alcançar pretensamente um amplo espectro didáticocientífico, no sentido de que as observações aqui apresentadas em discussão sobre o ensino remoto emergencial e as relações com o ensino de Matemática desenvolvido por meio de tecnologias digitais no âmbito do ERI, possibilitam ampliar o entendimento do processo de construção do conhecimento matemático dos profissionais envolvidos sobre a emergência de novas práticas de ensino, considerando-se alunos de licenciatura, professores de Matemática e de outras disciplinas científicas em todos níveis de escolaridades, prioritariamente sob o olhar crítico na formação inicial do futuro professor de Matemática no ambiente acadêmico e no exercício profissional.

A motivação crucial para o desenvolvimento desta proposta de reflexão mobilizando noções de modelos teóricos e documentos de modo articulado, foi compreender a noção de milieu sob a vigência do ERE incluso no ERI, especificamente o modelo propositivo do milieu didático virtual $(\mathrm{MD})_{V}$, pois entendemos que nesse construto as noções de customização e ergonomia constituem os principais pilares que sustentam sua infraestrutura didática, além de garantir o alinhamento efetivo com o trabalho docente.

Mas, se por um lado, a customização poderá garantir a personalização do $(M D)_{V}$ do aluno, no sentido amplo de integrar instrumentos materiais e imateriais que determinam possivelmente a fluidez ou não do ensino, guardadas as proporções, customizá-lo de certa maneira influencia na eficácia das aprendizagens singulares que poderão acontecer em torno do saber matemático, mais especificamente do objeto que está sendo abordado no processo de estudo, a ponto de promover ou não o sucesso na compreensão da estrutura matemática constituinte, suas aplicações e relações com outros objetos estudados 
anteriormente para o enfrentamento de novos problemas, como por exemplo, estudar a equação quadrática, sua natureza, relações e aplicações nos domínios aritmético, algébricos e geométricos.

Mas, essa singularidade das aprendizagens em Matemática certamente dependerá também da infraestrutura que será construída pelo aluno, mesmo que provisoriamente, especificamente do $(M D)_{V}$ que é engendrado pelo ERE sob a influência condicional do estado pandêmico; o usufruto proveitoso desse milieu pode ser encaminhado pela competência dos alunos e do professor, agentes da relação didática, em integralizar componentes adequados disponíveis para esse fim, tais como a escolha de plataformas, aplicativos de mensagens instantâneas, vídeos dentre outros condizentes com a natureza do objeto matemático de ensino. Mas, essa condicionante parece ter dificuldades de serem contornadas se considerarmos a emergencialidade e a urgência de implementação em contexto adverso e desafiador.

Por outro lado, a ergonomia joga um papel importante no $(M D)_{V}$ sob a orientação do ERE, a escolha dos componentes e plataformas tecnológicas adequados para o ensino, em particular de Matemática, indo além do significado de que a noção possa admitir de organização e otimização do trabalho docente, priorizando-se o desenvolvimento das atividades acadêmicas devendo sumariamente levar em consideração, sobretudo, fatores humanos, os quais interferem diretamente no processo de ensino e aprendizagem; não esqueçamos, pois, que o saber matemático é uma construção humana.

Destacamos que a noção de contrato didático tal qual a de milieu concatenadas motivou a proposição da noção de $(\mathrm{MD})_{\vee}$ que se institui em habitat determinado, a exemplo do amazônico; o documento regulatório - resolução do ERE - prescreveu as cláusulas, procedimentos e métodos a serem adotado na execução do ERE os quais certamente alinhados com o plano de trabalho docente de acordo com as especificidades de cada nicho possibilitam aulas remotas de forma síncrona e assíncrona por meio de plataformas e instrumentos tecnológicos digitais disponibilizados pelo ERI.

Certamente que respostas para nossa questão inicial - Como se instalou e se mantém o funcionamento das atividades acadêmicas, no contexto de pandemia e pós-pandemia, mediadas por tecnologias digitais via Milieux didático-virtual que se instituem diante do Ensino Remoto Emergencial (ERE) no ERI, de modo a garantir a qualidade do ensino, em particular, de Matemática? - tendo em conta o desafio de se adequar ao contexto pandêmico, foram sendo construídas, ainda que parcialmente, no desenvolvimento deste texto, podendo ao longo da vida do ERE, em movimento de retroação, serem aprimoradas à realidade virtual e remota para manter viva a mediação por inteligência artificial, oportunizando ao ensino de Matemática uma alternativa eficiente.

Portanto, entendemos claramente que a temática em foco sobre o uso de tecnologias digitais remotamente como prática de ensino ainda requer aprofundamentos e debates, mas, podem se integrar ao milieu institucional, percebemos a necessidade de confrontar nossa reflexão com dados da realidade objetiva não somente no âmbito da UFPA mas em diferentes instituições de ensino, aspecto que escapa aos nossos propósitos, porém vislumbramos a possibilidade de continuar implementado discussões sobre as alternativas para explorar a utilização da infraestrutura disponibilizada pelo ERI interna e externamente à UFPA.

Por fim, esperamos que esta reflexão de revisão e articulação teórico-propositiva possa contribuir de algum modo para fomentar as discussões sobre o uso efetivo do aparato 
institucional já estabelecido, assim como propor o debate à Educação Matemática, formação de professores, alunos, pesquisadores em Didática da Matemática e interessados em questões relacionadas à estrutura de funcionamento do ensino institucional, motivando novas investigações como por exemplo, estudar quais os impactos causados na formação docente durante a vigência do ensino remoto mediado por tecnologias digitais em uma dada instituição.

\section{Referências}

ALMOULOUD, S. A. Fundamentos da didática da matemática. Curitiba: Ed. UFPR, 2007. BROUSSEAU, G. Théorisation desphénomènes d'enseignement des mathématiques. Thèse pour le doctorat d'état - Université de Bordeaux I, 1986.

BROUSSEAU, G. Fundamentos e Métodos da Didáctica da Matemática. In: BRUN, Jean. Didática das Matemáticas. Lisboa: Instituto Piaget, 1986a. p. 35-113.

BROUSSEAU, G. Le contrat didactique: le milieu. Recherches En Didactique Des Mathématiques, v. 9, n. 3, p. 309-336, 1988.

BROUSSEAU, G. Glossaire de quelques concepts de la théorie des situations didactiques en mathématiques. In: BROUSSEAU, G. Dictionnaire de Didactique des mathématiques, 1988.

CHEVALLARD, Y. La transposición didáctica: Del saber sabio al saber enseñado. Buenos Aires: AIQUE, 1991.

CHEVALLARD, Y. Les processus de transposition didactique et leur théorisation. In: G. Arsac, Y. Chevallard, J.-L. Martinand, A. Tiberghien (Org.). La transposition didactique à l'épreuve, Grenoble: Editions La pensée sauvage, 1994. p. 135-180.

CHEVALLARD, Y. Un concept en émergence: la dialectique des médias et des milieux. Actes du séminaire national de didactique des mathématiques, 2007. p. 344-366.

CHEVALLARD, Y. La notion de PER: problèmes et avancées. Toulouse: IUFM, 2009.

MARGOLINA, C. La structuration du milieu et ses apports dans l'analyse a posteriori des situations. Les débats de didactique des mathématiques. In: Recherches en didactique des mathématiques . Grenoble: Editions La pensée sauvage, 1995. p.89-102.

RILHAC, P. (2007). Actions de l'élève et milieux didactiques: la notion de surassujettissement . Carrefours de l'éducation, v. 24, n. 2, p. 159-182, 2007.

PARÁ. Instrução Normativa n.001/2021, de 27 de setembro de 2021. Estabelece normas e procedimentos para o planejamento e a execução das medidas de retorno gradual à presencialidade das atividades de ensino e aprendizagem nos cursos de Graduação e Educação Básica, Técnica e Profissional (EBTP) da UFPA.Belem:PROEG,2021.

PARÁ. Resolução n. 5294/2020, de 21 de agosto de 2020. Aprova, de forma excepcional e temporária, o Ensino Remoto Emergencial em diferentes níveis de ensino para os cursos ofertados pela Universidade Federal do Pará, em decorrência da situação de pandemia do novo Coronavírus -COVID-19, e dá outras providências. Belém: CONSEPE,2020. 